\title{
No evidence of subgroups found in amphetamine consumers in Iran
}

\author{
Atireza Bananej · Sabine Völkl-Kernstock · Otto Lesch · Henriette Walter · Katrin Skala
}

Received: 30 September 2017 / Accepted: 8 February 2018 / Published online: 7 March 2018

(C) The Author(s) 2018. This article is an open access publication.

\begin{abstract}
Summary Amphetamine type substances are the second most commonly consumed illicit drug type and their use is an important contributor to the global burden of disease. This investigation set out to determine whether, similar to alcohol or nicotine addiction, subgroups of consumers can also be found in amphetamine addicts. 204 consumers of methamphetamine only $(n=50)$ or both methamphetamine and heroin $(n=154)$ have been investigated in Mashhad, Iran by means of "Lesch Alcoholism Typology". No significant differences in consumption pattern or age of onset have been found between the different types. Many subjects, however, reported symptoms of anxiety $(n=78)$ or depression $(n=129)$ prior to drug use. These findings highlight the need for high quality epidemiological studies further addressing this issue.
\end{abstract}

Keywords Amphetamines · Addiction · Subgroups

\section{Keine Belege für Subgruppen bei Amphetaminkonsumenten im Iran}

Zusammenfassung Substanzen aus der Gruppe der Amphetamine sind die weltweit am zweithäufigsten konsumierten illegalen Substanzen, ihr Konsum trägt in hohem Ausmaß zur weltweiten Morbiditätslast bei. Im Rahmen dieser Studie haben wir untersucht, ob bei Amphetaminabhängigen, ähnlich wie bei Alkoholoder Nikotinabhängigen, spezifische Untergruppen

\footnotetext{
A. Bananej · O. Lesch $\cdot$ H. Walter

Department of Psychiatry and Psychotherapy, Medical

University of Vienna, Vienna, Austria

S. Völkl-Kernstock · K. Skala $(\square)$

Department of Child and Adolescent Psychiatry,

Medical University of Vienna, Waehringer

Guertel 18-20, 1090 Vienna, Austria

katrin.skala@meduniwien.ac.at
}

gefunden werden können. In Mashhad (Iran) wurden 204 Konsumenten von Methamphetamin $(n=50)$ oder Methamphetamin und Heroin $(n=154)$ mittels „Lesch Alkoholism Typology“ untersucht. Wir fanden keine signifikanten Unterschiede in Bezug auf Konsummuster oder Alter bei Konsumbeginn. Viele Patienten gaben jedoch an, vor Beginn ihres Drogenkonsums unter Angstsymptomen $(n=78)$ oder depressiven Symptomen $(n=129)$ gelitten zu haben. Diese Ergebnisse zeigen, dass es qualitativ hochwertiger epidemiologischer Studien bedarf, um sich dieses Themas weiter anzunehmen.

Schlüsselwörter Amphetamine · Abhängigkeit · Untergruppen

\section{Introduction}

Illicit drug use is a global health concern and use of amphetamine-type substances (ATS) is an important contributor to the global burden of disease [6, 7]. The term ATS refers to various forms of stimulant drugs such as methamphetamine, amphetamine, methylenedioxymethamphetamine (MDMA, also known as "ecstasy"), methcathinone, and ephedrine. ATS are the second most commonly used type of illicit drug worldwide after cannabis (UNODC 29). In contrast with opioids, most use of amphetamine-group substances is non-injection. ATSs are most commonly snorted, smoked, or used rectally. Means of administration however varies substantially by region [11, 19]. Use of ATS can persist long term but, compared with opioids, most amphetamine-group substance use remains moderate [10]. In contrast to precursors of cocaine or opioid which can only be grown in regions with suitable climate and soil, amphetamine-group substances can be manufactured anywhere with access to the necessary ingredients. Together with the 
Table 1 Lesch types [17]

\begin{tabular}{|l|}
\hline Lesch Type I \\
\hline No psychiatric comorbidity \\
\hline Early and severe physical withdrawal of around 7 days \\
\hline Long-term treatment: regular counseling \\
\hline Lesch Type II \\
\hline Anxiety, alcohol is used for conflict solving or to counteract anxiety \\
\hline Mild physical withdrawal symptoms, duration around 14 days \\
\hline Long-term treatment: psychotherapy \\
\hline Lesch Type III \\
\hline Underlying affective disorder, alcohol is used to relieve negative affective \\
states \\
\hline Often episodic drinking pattern \\
\hline Mild physical withdrawal symptoms, duration up to 14 days \\
\hline Long-term treatment: diagnosis and treatment of comorbid condition, \\
psychotherapy \\
\hline Lesch Type $/ V$ \\
\hline Cognitive impairment (innate or subject to brain damage) \\
\hline Mild physical withdrawal symptoms, duration about 7 days \\
Long-term treatment: self-help groups, acceptance of relapse \\
\hline
\end{tabular}

fact that precursors are widely available and usually cheap, this accounts for the increased use of ATS use worldwide. Is has to be assumed that amphetaminegroup substances are manufactured in more than 60 countries [30].

While in Iran, an upper middle-income country with a population of 78 million in the west of Asia, opium and opium residues have historically been the traditional drugs of use [2], an increase of ATS use (with methamphetamine as the most frequently consumed substance) has taken place in recent years [1, 3]. While use of methamphetamines was scarce before 2005 [2, 3], investigations performed a few years later found that almost a quarter of subjects treated for opiate addiction were methamphetamine users [12] and that use had increased from $6 \%$ in 2009 to almost $20 \%$ in 2011 among former opiate addicts [14]. Despite this increase in certain subgroups, self-reported methamphetamine and ecstasy use has been found to amount to less than $1 \%$ in the general population [25].

\section{Subgroups of amphetamine users}

Despite a growing interest in identification of biomarkers for abuse of amphetamine-group substances, only few attempts have so far been made to distinguish different groups of users. There has however been an approach to differentiate social users, who consume amphetamine-group substances to enhance interpersonal interaction [9], and functional users, whose motivation includes the desire to lose weight, improve mood, enhance work performance, and counter fatigue [4, 27]. We assume that, like alcohol addiction, amphetamine addiction also comprises heterogeneous groups consuming the drug for various effects.
Table 2 Excerpt of structured interview according to the Lesch Alcoholism Typology

\begin{tabular}{|c|c|}
\hline $\begin{array}{l}\text { Addictive disorder among 1st degree } \\
\text { relatives? }\end{array}$ & (Yes/no) \\
\hline \multicolumn{2}{|l|}{ Age at onset of dependence ... } \\
\hline \multicolumn{2}{|c|}{ Leading substance is currently used against (multiple answers possible) } \\
\hline \multicolumn{2}{|l|}{$\begin{array}{l}\text { - anxiety } \\
\text { - depressed mood } \\
\text { - agitation } \\
\text { - withdrawal symptoms } \\
\text { - sleep disturbance } \\
\text { - to improve well-being } \\
\text { - other }\end{array}$} \\
\hline \multicolumn{2}{|c|}{ Childhood development up to the age of 14 : } \\
\hline Perinatal traumata: & (Yes/no) \\
\hline Cerebral traumata: & (None/mild/severe) \\
\hline Other cerebral diseases: & (Yes/no) \\
\hline Enuresis after the age of 3 : & (Yes/no) \\
\hline Nail biting ( $>6$ months): & (Yes/no) \\
\hline Stuttering (>6 months): & (Yes/no) \\
\hline \multicolumn{2}{|l|}{ Other diseases } \\
\hline Depressed mood: & (None/affective mood disorder) \\
\hline $\begin{array}{l}\text { Sleep disturbances without alcohol } \\
\text { intake: }\end{array}$ & $\begin{array}{l}\text { (None/disturbed sleep independent } \\
\text { of substance use or withdrawal) }\end{array}$ \\
\hline Suicidal or parasuicidal tendencies: & $\begin{array}{l}\text { (Never/only under influence of } \\
\text { substance or during withdrawal/ } \\
\text { independent of substance and } \\
\text { withdrawal) }\end{array}$ \\
\hline
\end{tabular}

The Lesch Typology of Alcoholism describes four subgroups of alcohol dependence [15]: subjects using alcohol mainly to cope with withdrawal symptoms (Type I- “biological addiction"), subjects using the drug to relieve symptoms of anxiety and tension (Type II-“anxiety-coping”), a group of consumers attempting to treat psychiatric comorbidity like depression or schizophrenia (Type III-“comorbidity"), and a group with cognitive impairment prior to the development of addiction (Type IV-“cognitive impairment"; [15-17]). The subgroups have been validated biologically and neurophysiologically (Table 1; [22, 28]). The main reason for choosing this typology has however been that clusters corresponding to those types had already been found in nicotine dependence [16].

\section{Aims of the study}

We assumed that, comparable to alcohol addicts, consumers of ATS also differ in the etiology of their addiction, their consumption behavior and predominantly consume for reasons like seeking stimulation, treating anxiety or depression, or coping with withdrawal. As type I includes subjects who quickly develop physical dependence to the substance in question, we did not expect to find subjects fitting this group in this sample.

In the present investigation we intended to determine whether amphetamine-dependent subjects 
Fig. 1 Decision tree for subgroups of amphetamine dependence
- Perinatal damage or

- Cerebral contusion or

- Other cerebral diseases or

Group IV

- Seizures or

- Nail biting and stuttering (both for months)

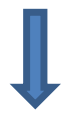

- Nocturnal enuresis (after the age of 3)

Group III or

Group IV

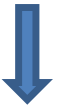

Nocturnal enuresis - "yes":

- No periodicity in smoking detectable or

- No sleep disorder or

Group IV

- No major depression or

- No suicidal tendencies

Nocturnal enuresis - "no":

- Periodicity in smoking detectable or

- Interrupted sleep or

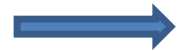

Group III

- Medium/severe depression (ICD-10) or

- Suicidal tendencies

Remaining categorie

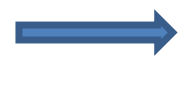

show differences that form a pattern comparable with that of alcohol dependence. As the Lesch Alcoholism Typology (Table 2) holds several items measuring addiction per se, we applied the Lesch typology to amphetamine addicts supposing that subtyping can be a further step towards the development of individualized treatment.

\section{Methods}

\section{Population and data collection}

The study population consisted of users of methamphetamine only $(n=50)$ and users of both methamphetamine and heroin $(n=154)$. Subjects were investigated at one of the official treatment centers for addiction in the city of Mashhad, where they had at that time been under outpatient treatment for their addic- tion. In the group investigated, methamphetamine was the only ATS consumed by the participants. Data were collected between April and August 2014. Data collection was conducted in addition to the standard procedure performed during their routine appointment at the outpatient clinic. Every subject was investigated by the same rater.

The study was approved by the Ethics Committee of the Therapeutic Community of Mashhad (B/1395/ ECTC). Informed consent was obtained from every participant.

\section{Measures}

The Lesch Alcoholism Typology (LAT) software (Scholz Informatik, Vienna), version 3.2.2, was used (Table 2 and Fig. 1). 


\section{Statistics}

$\mathrm{Chi}^{2}$ goodness-of-fit tests were used to investigate differences between groups (type II, III, IV) concerning substance use, age of onset, and duration of consumption. As the sample was small and data were dichotomous, Spearman's R was calculated as an additional means of interpretation.

Data analysis was conducted using IBM SPSS Statistics 21.0 software (SPSS Inc., Chicago, IL, USA).

\section{Results}

In the present sample 39 subjects (10 using methamphetamines only and 29 consuming both heroine and methamphetamines) fulfilled the criteria of type II, 75 subjects (25 users of methamphetamine and 50 users of methamphetamines and heroine) corresponded to type III, and 90 subjects met the criteria of type IV (15 users of methamphetamine and 75 users of methamphetamines and heroine). Type I describes the quick development of physical dependence to the substance investigated. As expected, subjects corresponding type I were not present in this sample.

Of the 204 participants, 149 subjects $(73 \%)$ were male and 55 subjects (27\%) were female. Five subjects were younger than 20 years, 183 were between 20 and 50 years old, and 16 were 50 years and older.

Time of treatment: The time of treatment was less than 1 month in 82 cases and between 1 and 2 months in 47 cases, while 48 subjects underwent treatment for 2-3 months, and 25 had treatment for 3 months or more.

Onset of consumption: Most subjects $(n=179)$ started consumption between the ages 20 and 50, 17 subjects were less than 20 , and 8 subjects were more than 50 years of age when they first consumed drugs. A total of 98 participants reported addictive disorders among immediate relatives.

Underlying psychopathology: While 78 participants said they had started taking drugs for their anxiety, as many as 129 participants reported to have started drug use in order to counteract states of depressed mood.

The inconsistencies of 39 participants fulfilling the criteria of Type II and 78 subjects using methamphetamine to counteract anxiety as well as 75 participants fulfilling criteria of Type III and 129 subjects trying to treat depressed mood states by means of the drug can be explained by the fact that subjects with a severe depressive disorder would occasionally suffer from anxiety (and would still be Type III) as would subjects with a diagnosis of anxiety disorder sometimes describe depressed mood states (and would still be Type II).
Suicidal tendencies: In all, 57 patients described suicidal tendencies independent of substance intake. Among these, suicidality was significantly more common in male subjects $(n=35)$ and in patients with neurodevelopmental problems $(n=90)$.

No significant differences in consumption pattern, time of treatment, onset of consumption, addictive disorders among relatives or suicidal tendencies have, however, been detected between the different types.

\section{Discussion}

Amphetamine-type substances, of which methamphetamine is the most frequently used, are more widely consumed than either opioids or cocaine. They are the second most commonly used class of illicit drugs worldwide and although the prevalence rates of current methamphetamine use have been relatively stable in the US in recent years [18], consumption is increasing in east and southeast Asia and the Middle East [30].

At present, treatment options have been limited to psychosocial interventions, most of which however lack evidence [26]. Numerous classes of medication are currently under study, but none has yet been proven to be sufficiently promising $[21,23]$.

Assuming that subtyping can be a further step towards the development of individualized treatment, this investigation set out to determine whether there are clusters of amphetamine-dependent subjects analogous to those found in alcohol-dependent patients. Other than in nicotine dependence [16] where different clusters of consumption could be found, no such differentiation was detected in our sample of amphetamine-dependent subjects.

Interestingly, however, and comparable to alcohol addiction, many amphetamine-dependent subjects seem to use the substances in order to treat mood disorders or disturbances. While it is known that amphetamines might lead to neurological and functional impairments, facilitating the development of depressive symptomatology [8, 20, 32], we saw that one third of our sample $(n=78)$ had initially started using amphetamines to treat symptoms of anxiety, while more than half of our subjects $(n=129)$ had started using amphetamines to treat symptoms of pre-existing depression.

Although articulate affective conditions prior to onset of amphetamine dependence have, to our knowledge, not been described before, these results fit in well with results from pharmacological trials. In these mainly substances targeting dopaminergic, serotonergic, GABAergic and glutamatergic brain pathways have so far been investigated for their potential in the treatment of amphetamine addiction [31]. Among the few substances that have proven promising in reducing methamphetamine use are two antidepressants, namely mirtazapine and buproprion [24]. Like topiramate, which is also being investigated to treat am- 
phetamine addiction, these drugs, however, show efficacy only in certain subgroups [5, 18].

So, even though articulate clusters could not be detected in this investigation it might still be useful to determine whether a patient exhibited symptoms of anxiety disorders (corresponding Type II) or depression (corresponding Type III) prior to the onset of addiction. These groups might benefit from different kinds of medications subject to their underlying condition.

The subgroups investigated here do not correspond to those already described, where consumers are classified into social users and functional users [4, 9, 27], but seem to be associated with underlying psychiatric conditions [13]. Future research that systematically addresses this gap might, thus, be able to provide support for effective treatment development for methamphetamine addiction.

\section{Limitations}

Among the various limitations of this investigation, the cross-sectional character, the small sample size, and the combination of subjects with differing consuming patterns are the most pre-eminent. Furthermore, the questionnaire is a self-rating tool and does not allow conclusions to be drawn on definite psychiatric disorders.

\section{Conclusion}

Although we did not identify conclusive evidence of subgroups in amphetamine addicts comparable to those described in alcohol or nicotine dependence, it was however interesting and novel to find such a large extent of reported pre-existing affective conditions prior to their drug use. These findings highlight the need for high quality epidemiological studies and closer monitoring of stimulant use in different populations.

Funding Open access funding provided by Medical University of Vienna.

Conflict of interest A. Bananej, S. Völkl-Kernstock, O. Lesch, $\mathrm{H}$. Walter, and K. Skala declare that they have no competing interests.

Open Access This article is distributed under the terms of the Creative Commons Attribution 4.0 International License (http://creativecommons.org/licenses/by/4.0/), which permits unrestricted use, distribution, and reproduction in any medium, provided you give appropriate credit to the original author(s) and the source, provide a link to the Creative Commons license, and indicate if changes were made.

\section{References}

1. Mehrjerdi AZ. Crystal in Iran: methamphetamine or heroin Kerack. Daru. 2013;21:22.

2. Alam-mehrjerdi Z, Abdollahi M, Higgs P, Dolan K. Drug use treatment and harm reduction programs in Iran: a unique model of health in themost populated Persian Gulf country. Asian J Psychiatr. 2015;16:78-83.

3. Alam-mehrjerdi Z, Mokri A, Dolan K. Methamphetamine use and treatmentin Iran: a review from the most populated Persian Gulf country. Asian J Psychiatr. 2015;16:17-25.

4. Cheng WS, Garfein RS, Semple SJ, Strathdee SA, Zians JK, Patterson TL. Diff erences in sexual risk behaviors among male and female HIV-seronegative heterosexual methamphetamine users. Am J Drug Alcohol Abuse. 2009;35:295-300.

5. Colfax GN, Santos GM, Das M, Santos DM, Matheson T, Gasper J, Shoptaw S, Vittinghoff E. Mirtazapine to reduce methamphetamine use: a randomized controlled trial. Arch Gen Psychiatry. 2011;68:1168-75.

6. Degenhardt L, Baxter AJ, Lee YY, Hall W, Grant ES, Johns $\mathrm{N}$, et al. The globalepidemiology and burden of psychostimulant dependence: findings from the global burden of disease study 2010. Drug Alcohol Depend. 2014;137:36-44.

7. Degenhardt L, Whiteford HA, FerrariAJ, Baxter AJ, Charlson FJ, Hall WD, Freedman G, Burstein R, Johns N, Engell RE, Flaxman A, Murray CJ, Vos T. Global burden of disease attributable to illicit drug use and dependence: findings from the Global Burden of Disease Study 2010. Lancet. 2013;382(9904):1564-74.

8. Gouzoulis-MayfrankE, Daumann J. Neurotoxicity of drugs of abused-the case of methylenedioxyamphetamines (MDMA, ecstasy), and amphetamines. Dialogues Clin Neurosci. 2009;11:305e17.

9. Halkitis PN, Solomon TM, Moeller RW, et al. Methamphetamine use among gay, bisexual and non-identifi ed men-who-have-sexwith-men: an analysis of daily patterns. JHealth Psychol. 2009;14:222-31.

10. Hser YI, Huang D, Brecht ML, Li L, Evans E. Contrasting trajectories of heroin, cocaine, and methamphetamine use. JAddict Dis. 2008;27:13-21.

11. Inglez-Dias A, Hahn JA, Lum PJ, Evans J, Davidson P, Page-Shafer K. Trends in methamphetamine use in young injection drug users in San Francisco from 1998 to 2004: the UFO Study. DrugAlcohol Rev. 2008;27:286-91.

12. Jafari S, Noroozi A, Razzaghie EM, Shafiee SA, Naghshvarian $\mathrm{M}$. How to address methamphetamine involvement in OST settings. Harm Reduction's 22ND International Conference; Beirut. :;2011. http://www.ihra.net. Accessed 23 May 2017.

13. Karila L, Weinstein A, Aubin HJ, Benyamina A, Reynaud M, Batki SL. Pharmacological approaches to methamphetamine dependence: a focused review. Br J Clin Pharmacol. 2010;69:578-92.

14. Lashkaripour K, Torbati E. Methamphetamine dependence. Int J High Risk Behav Addict. 2012;1:7-8.

15. Lesch OM, Bonte W, Kefer J, Mader R, Musalek M, Nimmerrichter A, Sprung R, Walter H. A new typology in chronic alcoholism and its biological markers. Alcohol Alcohol. 1989;24:380.

16. Lesch OM, Dvorak A, Hertling I, Klingler A, Kunze M, Ramskogler K, Saletu-Zyhlarz G, Schoberberger R, Walter H. The Austrian multicentre study on smoking: subgroups of nicotine dependence and their craving. Neuropsychobiology. 2004;50(1):78-88.

17. Lesch OM, Walter H. Subtypes of alcoholism and their role in therapy. Alcohol Alcohol. 1996;31:63-7. 
18. Ma JZ, Johnson BA, Yu E, Weiss D, McSherry F, Saadvandi J, Iturriaga E, Ait-Daoud N, Rawson RA, Hrymoc M, Campbell J, Gorodetzky C, et al. Fine-grain analysis of the treatment effect of topiramate on methamphetamine addiction with latent variable analysis. Drug Alcohol Depend. 2013;130:45-51.

19. Matsumoto T, Kamijo A, Miyakawa T, et al. Methamphetamine in Japan: the consequences of methamphetamine abuse as a function of route of administration. Addiction. 2002;97:809-17.

20. McKetin R, Dawe S, Burns RA, Hides L, Kavanagh DJ, Teesson M, McDYoung R, VoceA, Saunders JB. The profile of psychiatric symptoms exacerbated by methamphetamine use. Drug Alcohol Depend. 2016;161:104-9.

21. Morley KC, Cornish JL, Faingold A, Wood K, Haber PS. Pharmacotherapeutic agents in the treatment of methamphetamine dependence. Expert Opin Investig Drugs. 2017;26(5):563-78.

22. MusshoffF,DaldrupT,BonteW,LeitnerA,LeschOM.Salsolinol and norsalsolinol in human urine samples. Pharmacol Biochem Behav. 1997;58:545-50.

23. National Institute on Drug Abuse (NIDA). Medications development research for treatment of amphetamine and methamphetamine addiction. Bethesda: U.S. Department of Health and Human Services, National Institutes of Health; 2005.

24. Newton TF, Roache JD, De La Garza R 2nd, Fong T, Wallace CL, Li SH, Elkashef A, Chiang N, Kahn R. Bupropion reduces methamphetamine-induced subjective ef- fects and cue-induced craving. Neuropsychopharmacology. 2006;31:1537-44.

25. Shadloo B, Amin-Esmaeili M, Haft-Baradaran M, Noroozi A, Ghorban-Jahromi R, Rahimi-Movaghar A. Use of amphetamine-type stimulants in the Islamic Republic of Iran, 2004-2015: a review. East Mediterr Health J. 2017;23(3):245-56.

26. Shearer J. Psychosocial approaches to psychostimulant dependence: a systematic review. J Subst Abuse Treat. 2007;32:41-52.

27. Sherman SG, SutcliffCG, German D, Sirirojn B, Aramrattana A, Celentano DD. Patterns of riskybehaviors associated with methamphetamine use among young Thai adults: a latent class analysis. JAdolesc Health. 2009;44:169-75.

28. SperlingW, FrankH, Martus P, Mader R, Barocka A, WalterH, Lesch OM. The concept of abnormal hemispheric organization in addiction research. Alcohol Alcohol. 2000;35:394-9.

29. UNODOC 2008 World Drug report. https://www.unodc. org/documents/wdr/WDR_2008/WDR_2008_eng_web. pdf. Accessed 24.2.2018.

30. UN Office on Drugs and Crime. World drug report 2012. New York: United Nations; 2012.

31. Vocci FJ, Appel NM. Approaches to the development of medications for the treatment of methamphetamine dependence. Addiction. 2007;102(Suppl 1):96-106.

32. Zweben JE, Cohen JB, Christian D, et al. Psychiatric symptoms in methamphetamine users. Am J Addict. 2004;13:181e90. 